\title{
Influence of Different Surface Treatments on the Fracture Toughness of a Commercial ZTA Dental Ceramic
}

\author{
Flavio Teixeira da Silva ${ }^{\mathrm{b} *}$, Marcio Alessandro Negrelly Zacchéa, ${ }^{\mathrm{a}, \mathrm{b}}$, Helio Salim de Amorim ${ }^{\mathrm{c}}$ \\ aniversidade Veiga de Almeida \\ ${ }^{\mathrm{b}}$ Programa de Engenharia Metalurgica e de Materiais - PEMM - COPPE/UFRJ \\ Universidade Federal do Rio de Janeiro, Centro de Tecnologia, Bloco F, Sala - F-210, \\ 21941-972 Rio de Janeiro - RJ, Brazil \\ 'Universidade Federal do Rio de Janeiro - IF/UFRJ
}

Received: July 5, 2006; Revised: January 8, 2007

\begin{abstract}
The objective of this study was to investigate how mechanical surface treatments performed for removal of excess of molten glass, influence the fracture toughness of a dental zirconia toughened alumina (In-Ceram ${ }^{\circledR}$ Zirconia). Infiltrated ZTA disks were submitted to three different surface treatments (grinding, sandblasting and grinding + sandblasting + annealing). Fracture toughness was accessed through indentation strength test (IS). $\mathrm{X}$ ray diffraction was used to investigate the metastability of tetragonal zirconia particles under all treatments proposed. Kruskall-Wallis non-parametrical test and Weibull statistics were used to analyze the results. Grinding (group 1) introduced defects which decreased the fracture toughness and reliability, presenting the lowest $\mathrm{K}_{\mathrm{IC}}$. On the other hand, grinding followed by sandblasting and annealing (group 3) presented the highest $\mathrm{K}_{\mathrm{IC}}$. Sandblasting (group 2) presented the highest reliability but lower $\mathrm{K}_{\mathrm{IC}}$ compared to group 3.
\end{abstract}

Keywords: dental ceramic, fracture toughness, transformation toughening, Weibull distribution

\section{Introduction}

The loss or destruction of teeth due to periodontal disease, caries or trauma, have lead dentistry and engineering professionals to develop new materials and search for prosthetic treatments for the replacement of those missing teeth.

Until recently, all ceramic restorations were indicated only for single crowns and partial coverage restorations due to their low flexural strength and fracture toughness.

Many all ceramic systems were developed with the goal to improve the possible indications of metal free restorations. Among these, the zirconia based systems are the most promising for achieving the objective of substitute metalceramic restorations. The In-Ceram ${ }^{\circledR}$ Zirconia (Vita Zahnfabrik, Bäd Sackingen - Germany) is composed of $\alpha$-alumina with $33 \mathrm{w} \%$ partially stabilized zirconia (12 mol\% Ceria), partially sintered in two steps at low temperature $\left(1120\right.$ and $\left.1180{ }^{\circ} \mathrm{C}\right)$ to avoid shrinkage, followed by glass infiltration at $1140{ }^{\circ} \mathrm{C}$, resulting in a dense and high strength ceramic core material, mainly used for replacing posterior teeth with all ceramic restorations. The processing steps are similar to the well known In-Ceram ${ }^{\circledR}$ Alumina technique ${ }^{1}$.

The effect of dispersed zirconia grains in an alumina matrix, increasing its mechanical properties is known as transformation toughening. When a stress is applied to the structure, zirconia grains undergo an allotropic transformation (from tetragonal to monoclinic) in the presence of a growing crack; this transformation results on an increase in volume (3-5\%), that leads to a compressive stress field opposing crack propagation. This $t$-m transformation by an applied stress is similar to that observed on martensitic transformation in quenched steels ${ }^{2-8}$.

Although the relationship between mechanical properties and their clinical performance are influenced by many factors, some of these, namely flexural strength and fracture toughness, have been used as initial parameters to determine the clinical potential and limitations of these materials ${ }^{2}$.

There is a straight relationship between strength and fracture toughness in brittle materials, where the critical defect size to initiate failure is determined by the inherent flaw population introduced during material processing and component manufacture ${ }^{3,4,9,10}$. In zirconia based materials, such flaw population could be influenced by surface treatments as grinding and/or sandblasting, and it may alter the relationship between tetragonal and monoclinic zirconia ${ }^{4,5,7,11-13}$.

The toughening mechanism of ZTA ceramics due to surface treatments (grinding and/or sandblasting) is based upon the development of a compressive surface layer related to the tetragonal-monoclinic transformation and generation of microcracks ${ }^{6,7,9}$. The strengthening of ground zirconia toughened ceramics depends, for instance, on the amount of transformed zirconia on the deepest region of the compressive surface layer, which increases with grinding intensity. Otherwise, severe grinding and reverse $m$ - $t$ transformation due to heat generation may cause cracks that could extend beyond the compressive surface layer, causing a drastic decrease in its mechanical properties ${ }^{3,4,8}$.

Moon et al. ${ }^{14}$ reported that sandblasting promotes the nucleation of dislocations and microcracks due to the $t-m$ transformation, and a compressive state at the surface, without any increase in temperature. An annealing treatment after sandblasting may recover almost all tetragonal phase lost during this surface treatment, in such way that the recovered tetragonal zirconia grains were capable to readily transform to monoclinic under an applied stress.

The aim of the present work was to investigate which kind of mechanical surface treatment in a commercial dental ZTA (In-Ceram ${ }^{\circledR}$ 
Zirconia) could result in minor loss of transformable tetragonal zirconia and higher fracture toughness. In the present paper, the adopted fracture toughness test was the indentation strength (IS).

\section{Materials and Methods}

Thirty six disks of In-Ceram ${ }^{\circledR}$ Zirconia were slip casted according to manufacture's instructions $(25 \mathrm{~mm}$ diameter and $2.5 \mathrm{~mm}$ height). Partial sintering was carried out in two steps. First step at $1120^{\circ} \mathrm{C}$ for 2 hours with 6 hours drying at $120^{\circ} \mathrm{C}$. Second sintering at $1180{ }^{\circ} \mathrm{C}$ for 2 hours with a heating rate of $8{ }^{\circ} \mathrm{C} /$ minutes. At this temperature, very little densification is achieved. Samples were then glass infiltrated for densification at $1140{ }^{\circ} \mathrm{C}$ for 4 hours with a heating rate of $8{ }^{\circ} \mathrm{C} /$ minutes, and then allowed to cool to room temperature inside the furnace. In order to investigate the influence of three different mechanical surface treatment related to excess of molten glass removal after the infiltration process on ZTA disks, three groups of 12 discs were selected: grinding (group 1), sandblasting (group 2) and grinding, sandblasting and annealing (group 3). One indentation was introduced on the center of each sample through a Vickers indenter with two different loads (59 and $98 \mathrm{~N}$ ).

In order to calculate the fracture toughness by indentation strength (IS), young modulus and hardness are needed: Young modulus was determined from a nondestructive ultra-sound test $(n=4)$ (Krautkramer mod. USIP 12 with an oscilloscope Tektronics mod. TPS 420A) and Vickers hardness $(n=4)$ according to ASTM C1327-99. Figure 1 shows the apparatus used in the fracture toughness tests.

Fracture toughness was calculated from the equation proposed by Chantikul et al. ${ }^{15}$;

$$
\mathrm{K}_{\mathrm{IC}}=0.59(\mathrm{E} / \mathrm{H})^{1 / 2}\left(\mathrm{~S}_{\mathrm{f}} \mathrm{P}^{1 / 3}\right)^{3 / 4}
$$

where:

$\mathrm{E}$ - Young modulus $=255 \mathrm{GPa}$ (mean), $\mathrm{H}$ - Vickers hardness $=9.8 \mathrm{GPa}$ (mean), $\mathrm{P}=$ load at the moment of fracture $(\mathrm{N}), \mathrm{S}_{\mathrm{f}}$ stress at the moment of fracture $(\mathrm{MPa})=-2387 \mathrm{P}(\mathrm{X}-\mathrm{Y}) / \mathrm{d}^{2}$, as suggested by ASTM F394-78, where $d=$ sample thickness $(\mathrm{mm}), X=(1+v) \ln \left(\mathrm{r}_{2} / \mathrm{r}_{3}\right)+$ $[(1-v) / 2]\left(r_{2} / r_{3}\right)^{2}$ and $Y=(1+v)\left[1+\ln \left(r_{1} / r_{3}\right)^{2}\right]+(1-v)\left(r_{1} / r_{3}\right)^{2}$ $\mathrm{r}_{1}-$ Radius of supporting circle $(\mathrm{mm})$;

$\mathrm{r}_{2}$ - Radius of the loading ball $(\mathrm{mm})$;

$\mathrm{r}_{3}$ - Radius of the sample disk ( $\left.\mathrm{mm}\right)$; and

$v$ - Poisson ratio $=0.23$.

Statistical analysis was made using Kruskall-Wallis non-parametrical test ${ }^{16,17}$. The cumulative probability of failure $\mathrm{X}$ normalized fracture toughness plot, similar to a Weibull ${ }^{18}$ plot for flexural tests was also accessed. This analysis was conducted in order to evaluate the reliability of infiltrated ZTA disks submitted to the three different mechanical surface treatments. The influence of mechanical surface treatment on the tetragonal-monoclinic transformation was evaluated quantitatively by $\mathrm{x}$ ray diffraction. The specimens were scanned with $\mathrm{Cu}-\mathrm{K} \alpha(30 \mathrm{KV}-20 \mathrm{~mA})$ radiation and Bragg angle varying from 26 to $32.5^{\circ}$, at a $0.05^{\circ}$ step and 4.0 seconds interval. It was also performed $\mathrm{x}$ ray diffractions of the starting powder and after sintering cycles. The fractured disks were analyzed by SEM (Jeol 5800LV).

\section{Results}

$\mathrm{X}$ ray diffraction of In-Ceram ${ }^{\circledR}$ Zirconia starting powder and of one sample after the second sintering is shown in Figure 2. In terms of tetragonal/monoclinic zirconia content, it can be seen that tetragonal zirconia is the predominant phase. It is also clear that tetragonal zirconia content increased after sintering $\left(1180{ }^{\circ} \mathrm{C}\right)$, which is an evidence that the starting powder was originally milled.

The mean and standard deviation of fracture toughness by indentation strength (IS) are shown in Table 1. The indentation tests were

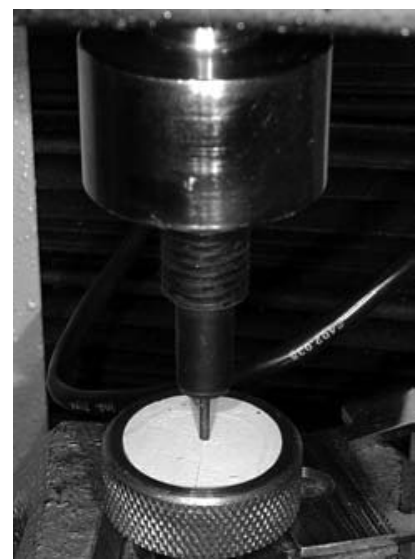

(a)

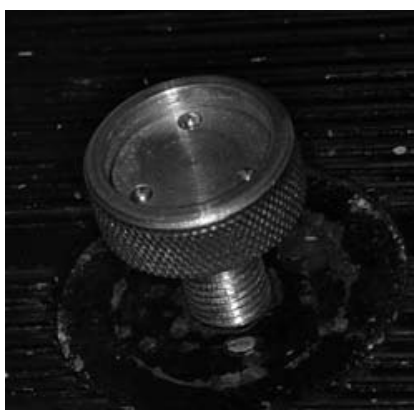

(b)
Figure 1. Mechanical apparatus used in indentation strength tests of ZTA disks

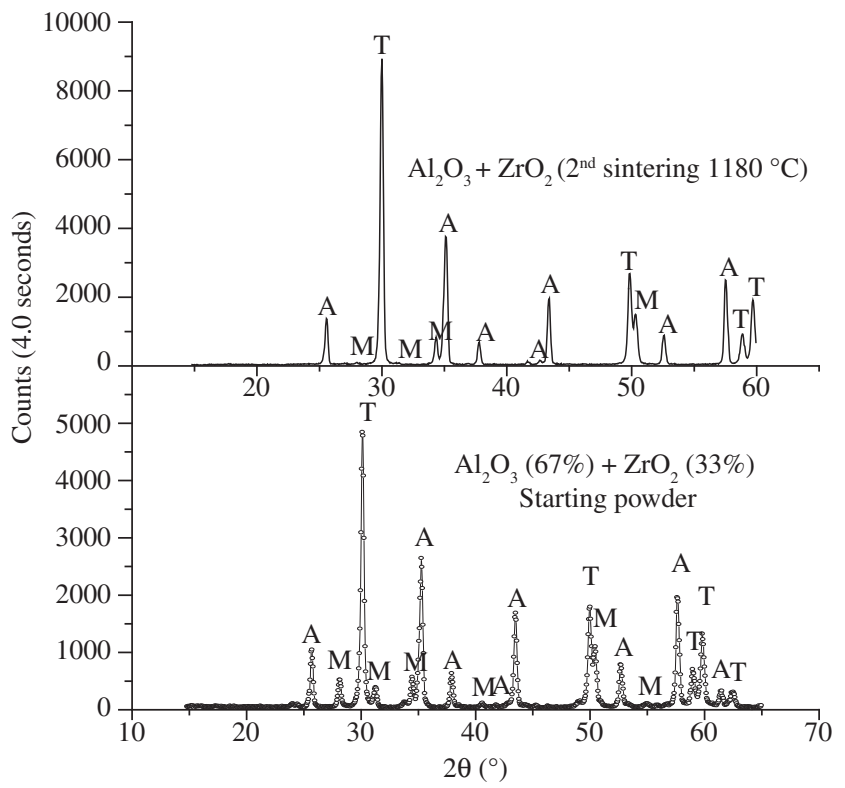

Figure 2. X ray diffraction of In-Ceram ${ }^{\circledR}$ Zirconia starting powder and after sintering.

Table 1. Mean and standard deviation of fracture toughness (IS) for the three groups. Different letters indicates statistic difference among groups.

\begin{tabular}{cccc}
\hline Surface treatment & $\mathrm{K}_{\mathrm{IC}}$ & $\sigma$ & Significance $\alpha=0.05$ \\
\hline Group 1 & 4.557 & 0.292 & $\mathrm{~A}$ \\
Group 2 & 4.759 & 0.201 & $\mathrm{~B}$ \\
Group 3 & 4.919 & 0.250 & $\mathrm{C}$ \\
\hline
\end{tabular}

only validated if the crack began at the corners of Vickers indentation. Different letters indicate statistical difference between groups.

Weibull distribution of the three groups is shown in Figure 3. In grinded samples (group 1), $\mathrm{K}_{\mathrm{IC}}$ values could be represented by a straight line as expected for a normal Weibull distribution $\left(\mathrm{R}^{2}=0.93\right)$, otherwise groups ( 2 and 3 ), did not. From equation 1 it was observed that the indentation load may affect $\mathrm{K}_{\mathrm{IC}}$. Due to this fact, those results could not be represented by a normal Weibull distribution, but by a 


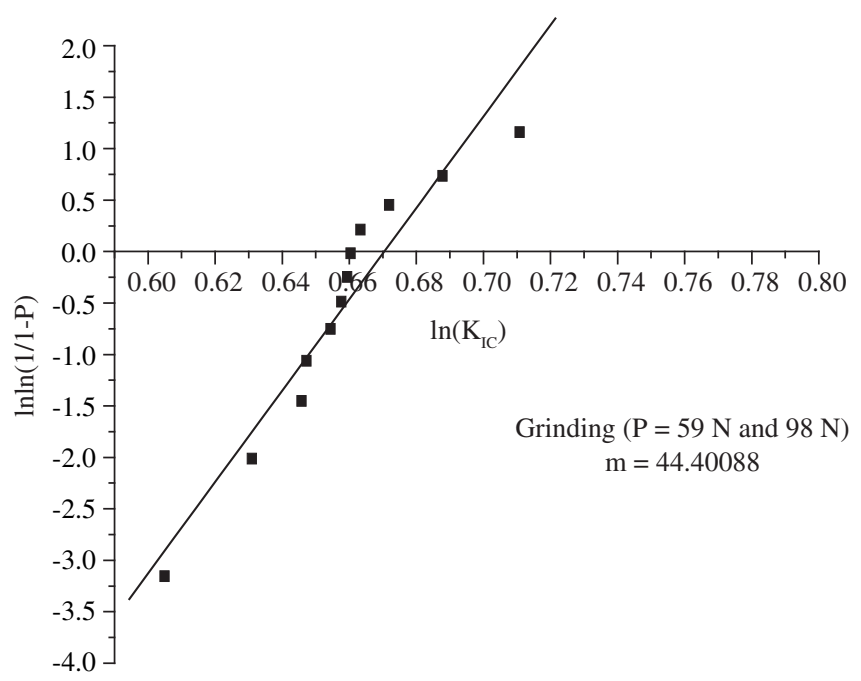

(a)

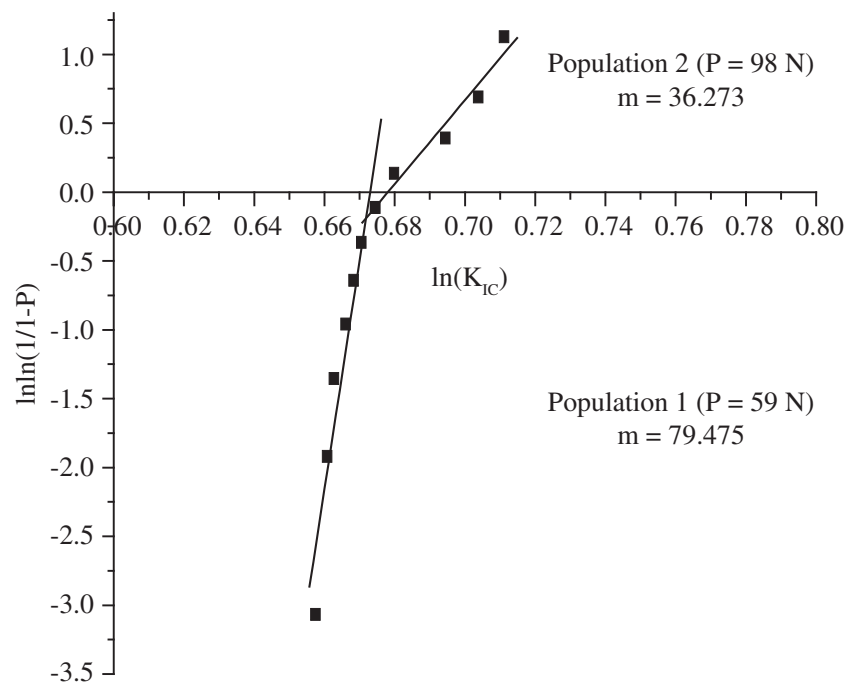

(b)

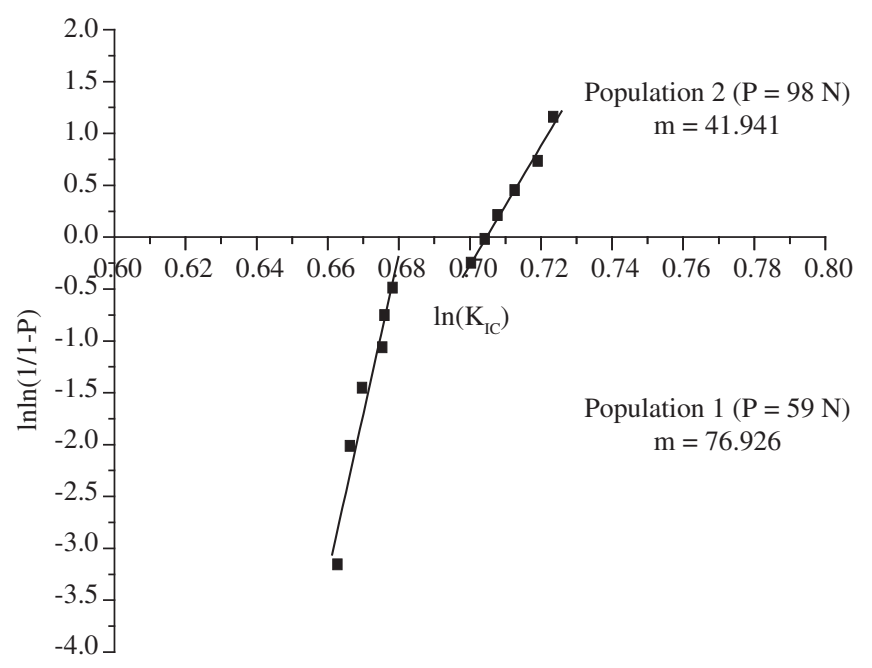

(c)

Figure 3. Weibull distribution of fracture toughness by indentation strength $(\boldsymbol{I S})$ of the ZTA disks submitted to the three different mechanical surface treatments: a) grinding; b) sandblasting; c) grinding + sandblasting + annealing. multiple one, which would result in two mutually excluding defect population, each one representative of one indentation load. On group 1, this behavior was not observed, once there was no correlation between the indentation load and $\mathrm{K}_{\mathrm{IC}}$.

From the expression of the flexural strength of a brittle material composed by two mutually excluding defect populations, a new one was developed for the Weibull distribution of $\mathrm{K}_{\mathrm{IC}}$.

$$
\mathrm{P}\left(\mathrm{K}_{\mathrm{IC}}\right)=\pi \mathrm{P}_{1}\left(\mathrm{~K}_{\mathrm{IC}}\right)+(1-\pi) \mathrm{P}_{2}\left(\mathrm{~K}_{\mathrm{IC}}\right)
$$

Considering that each population could be described by a single Weibull distribution:

$$
\begin{aligned}
& \mathrm{P}\left(\mathrm{K}_{\mathrm{IC}}\right)=1-\pi \exp \left[-\left(\mathrm{K}_{\mathrm{IC}} / \mathrm{K}_{\mathrm{IC1}}\right)^{m 1}\right]- \\
& (1-\pi) \exp \left[-\left(\mathrm{K}_{\mathrm{IC}} / \mathrm{K}_{\mathrm{IC} 2}\right)^{m 2}\right]
\end{aligned}
$$

where $\pi$ represents the sample fraction loaded with $59 \mathrm{~N}$ and $1-\pi$ for those loaded with $98 \mathrm{~N}$. $\mathrm{K}_{\mathrm{IC1}}, \mathrm{K}_{\mathrm{IC} 2}, m_{1}$ e $m_{2}$ are distribution parameters, as it can be seen in Table 2 .

The influence of mechanical surface treatments on the mechanical behavior of ZTA disks were evaluated in the light of the transformation toughening mechanism due to the tetragonal/monoclinic transformation. Figure 4 shows the $\mathrm{x}$ ray diffraction of a grinded (group 1) and sandblasted (group 2) sample. It can be seen an enlargement of the tetragonal (111) base peak of the grinded sample, indicating some disruption of the lattice parameters due to the grinding treatment. Figure 5 shows the $\mathrm{x}$ ray diffraction of one sample at two different moments: after grinding, where it can be seen some disruption of the lattice parameters represented by an enlargement of the base of the tetragonal (111) peak; and after an annealing treatment at $1000{ }^{\circ} \mathrm{C}$ for 30 minutes, where it it can be seen an increase in height and decrease in thickness of the same (111) tetragonal peak. Figure 6 shows the superposition of the $\mathrm{x}$ ray diffraction of a non-infiltrated sample and of the molten glass. It can be seen an overlapping of a non-identified peak (associated to the glass infiltration process) with the $(11 \overline{1})$ monoclinic peak. From the expression of the relative amount of transformed monoclinic zirconia developed by Garvie and Nicholson ${ }^{19}$ and Gregory et al. ${ }^{20}$, it was developed Equation 4, ex-

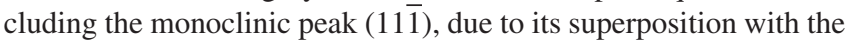
glass phase peak:

$$
X_{m}=2.658 \times I_{m}(111) / 2.658 \times I_{m}(111)+I_{t}(111)
$$

From Equation 4, the amounts of transformed monoclinic zirconia due to the different mechanical surface treatments were quantified, as shown in Table 3.

\section{Discussion}

Many studies concerning the effect of grinding on advanced ceramics had been carried out and still are being made ${ }^{4-7,11,12}$. It seems to be an agreement that the influence of grinding on microstructure and mechanical properties of zirconia based ceramics depends on many factors, such as: type and amount of stabilizer, processing steps, type of abrasive and degree of grinding (speed, pressure and cooling), as well as the nature and size of the surface compressive layer introduced by grinding.

The results of fracture toughness tests revealed that the type of mechanical surface treatment affects the behavior of a propagating crack as shown in Table 1. Group 1 (grinding) presented the lowest $\mathrm{K}_{\mathrm{IC}}$ mainly due to the high flaw density and defects introduced by grinding. In fact, in order to achieve a complete removal of the exceeding molten glass from the samples surface, an aggressive grinding must be performed. So, it is expected that such stressing treatment would result in lower toughness. XRD also supports the results of mechanical performance, since the disruption of lattice parameters are evident (Figure 4 and 5). 
Table 2. $\mathrm{K}_{\mathrm{IC}}$ and apparent Weibull modulus $(m)$ of indentation strength tests (IS) for the different groups.

\begin{tabular}{|c|c|c|c|c|c|c|c|c|c|}
\hline \multirow{2}{*}{\multicolumn{2}{|c|}{ Group 1}} & \multirow{2}{*}{\multicolumn{4}{|c|}{ Group 2}} & \multicolumn{4}{|c|}{ Group 3} \\
\hline & & & & & & \multicolumn{4}{|c|}{$\pi=0.4217$} \\
\hline $\mathrm{K}_{\mathrm{IC}}$ & $m$ & $\mathrm{~K}_{\mathrm{IC} 1}$ & $m_{1}$ & $\mathrm{~K}_{\mathrm{IC} 2}$ & $m_{2}$ & $\mathrm{~K}_{\mathrm{IC} 1}$ & $m_{1}$ & $\mathrm{~K}_{\mathrm{IC} 2}$ & $m_{2}$ \\
\hline 4.55 & 44.401 & 4.65 & 79.475 & 5.04 & 36.273 & 4.71 & 76.926 & 5,17 & 41.941 \\
\hline
\end{tabular}

Table 3. Amounts of transformed zirconia monoclinic after the three different mechanical surface treatments.

\begin{tabular}{|c|c|c|c|c|c|c|c|c|}
\hline \multirow[t]{2}{*}{ Group } & \multicolumn{3}{|c|}{ Sample 1} & \multicolumn{3}{|c|}{ Sample 2} & \multirow[t]{2}{*}{ Mean $X_{\mathrm{m}}(\%)$} & \multirow[t]{2}{*}{ Mean $\mathrm{X}_{\mathrm{T}}(\%)$} \\
\hline & monoclinic (111) & tetragonal (111) & $\mathrm{Xm}(\%)$ & monoclinic (111) & tetragonal (111) & $\mathrm{Xm}(\%)$ & & \\
\hline 1 & 29.45 & 4424.0 & 1.73 & 24.65 & 3903.0 & 1.65 & 1.69 & 98.31 \\
\hline 2 & 67.8 & 2478.3 & 6.77 & 49.7 & 709.1 & 15.7 & 11.23 & 88.77 \\
\hline 3 & 7.88 & 5091.4 & 0.41 & 9.0 & 4025.8 & 0.59 & 0.50 & 99.50 \\
\hline
\end{tabular}

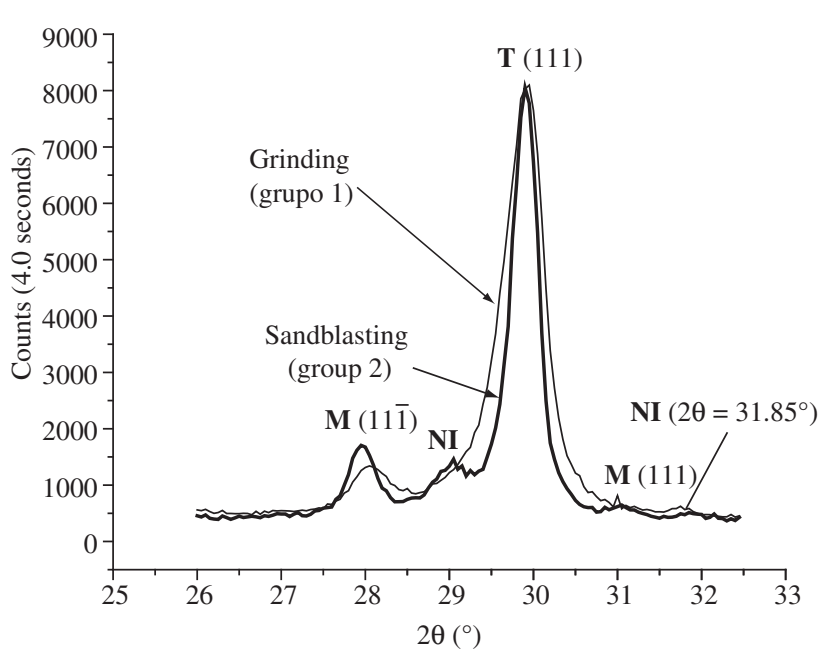

Figure 4. $\mathrm{X}$ ray diffraction of infiltrated ZTA disks after two different mechanical surface treatments: Grinding (group 1) and sandblasting (group 2). It can be seen an enlargement of the tetragonal base peak (111) of grinded sample indicating some disruption of the lattice parameters due to the grinding treatment. $\mathrm{NI}=$ non-identified peak.

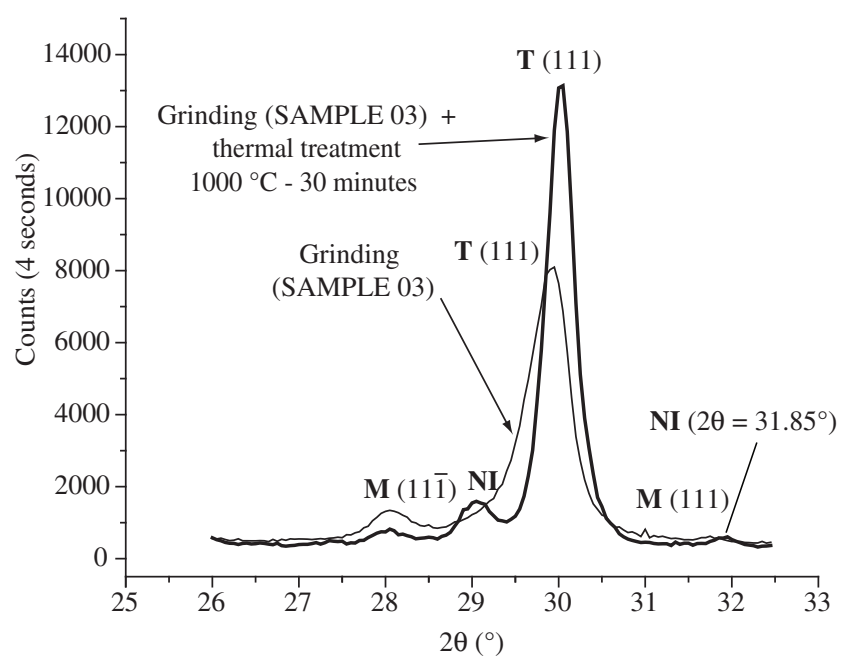

Figure 5. $\mathrm{X}$ ray diffractions of a single ZTA sample at two moments: after grinding and after a heat treatment. $\mathrm{NI}=$ non-identified peak.

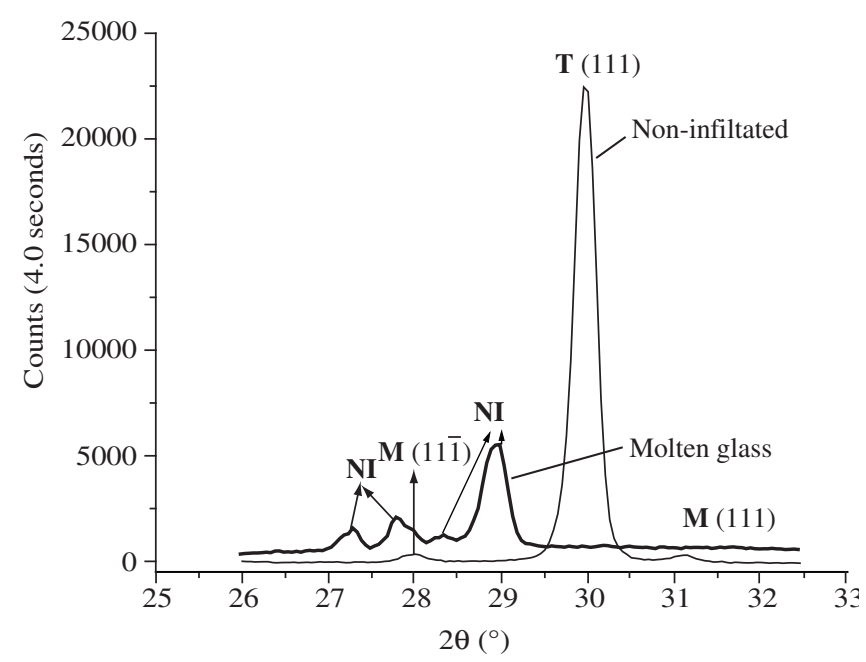

Figure 6. X ray diffractions of a non-infiltrated ZTA and a ZTA covered by a thick layer of infiltrated glass. Note the superposition of the non-identified glass peak with the monoclinic (11̄).

It indicates that high stress and plastic deformation are present. In this case, there was no correlation between indentation load and $\mathrm{K}_{\mathrm{IC}}$. Weibull analysis revealed that such treatment leads to a less reliable material since both indentations were scattered within the plotted data.

On the other hand, group 2 (sandblasting) seems to be a less aggressive and uniform treatment, showing much less harmful effect on the lattice parameters compared to grinded samples (Figure 4), thus leading to an increase in $\mathrm{K}_{\mathrm{IC}}$ and Weibull modulus. The high amount of monoclinic zirconia (Table 3), reveals that there were nearly no heat generation during surface treatment. In the present study, pressure and particle size of abrasive followed manufacturer recommendation $\left(50 \mu \mathrm{m}\right.$ at 3 bar). Guazzato et al. ${ }^{13}$ reported that a rough and damaged surface could be observed after sandblasting, but these defects were not as large as the defects observed after grinding. In fact, Kosmak et al. ${ }^{4}$ observed that after sandblasting, the thickness of the transformed surface layer was found to be larger than in ground samples, indicating that not only stresses, but also the locally developed temperatures during sandblasting were lower. This improvement in strength was not observed by Guazzato et al. ${ }^{13}$. They argued that the damage on the surface and high stresses generated by the abrasive particles were only partially counteracted by the tetragonal-monoclinic 
transformation, resulting in strength degradation and lower Weibull modulus. Although both authors used the same abrasive $(110 \mu \mathrm{m}$ alumina particles), they used different pressures, one of them using extreme unjustified high pressure $(5 \mathrm{MPa}-50 \mathrm{bar})^{13}$, which could be responsible for those differences. On our work, higher $\mathrm{K}_{\mathrm{IC}}$ and reliability were attained after sandblasting. Although the results from XRD are very similar to the results observed by other studies ${ }^{2,4,13,21}$, the mechanical performance and reliability of sandblasted specimens obtained by Guazzato et al. ${ }^{13}$, revealed that not only the abrasive grit but pressure employed on sandblasting, play an important role on the mechanical performance of zirconia ceramics. Based on these facts, caution should be taken when considering the effect of sandblasting on the mechanical properties of zirconia based ceramics. Under low pressures, only the very surface of zirconia particles undergoes the tetragonal-monoclinic transformation, causing the flaws and defects to be very small, not exceeding the thickness of the compressive surface layer and yet promoting microcrack toughening. Otherwise, higher pressure would tend to produce larger flaws that could exceed the thickness of the surface layer, and even promoting the pullout of some particles, thus not altering the amount of monoclinic zirconia at the surface.

Group 3 (grinding followed by sandblasting and annealing) presented the highest $\mathrm{K}_{\mathrm{IC}}$. An annealing treatment after grinding and sandblasting may promote crack healing in the glass matrix and a partial recover of tetragonal zirconia lost during both treatments. These results were confirmed through $\mathrm{x}$ ray diffraction (Figure 5).

$\mathrm{X}$ ray diffraction of the molten glass revealed the nucleation of crystalline phases, some of these peaks with Bragg angle similar to the $(11 \overline{1})$ plane of monoclinic zirconia, overestimating the amount of monoclinic zirconia (Figure 6). Due to this behavior, the suggested expressions for the quantification of tetragonal and monoclinic zirconia by $\mathrm{x}$ ray diffraction proposed by Garvie and Nicholson ${ }^{19}$ and by Gregory et al..$^{20}$, do not express the reality. From these equations, a new one was obtained not taking into account the (11) peak of monoclinic zirconia. Other studies ${ }^{2,13,21}$ concerning this material did not observe this overlapping, thus leading to an overestimation of monoclinic zirconia. The Weibull distribution of group 3 shows that the heat treatment proposed was not able to anneal out all stresses and disruption introduced specially by grinding process. The reason is that the annealing treatment $\left(1000^{\circ} \mathrm{C} / 5\right.$ minutes $)$ was not able to allow such recover. It is expected that a heat treatment for a longer time $\left(1000^{\circ} \mathrm{C} / 30\right.$ minutes $)$ could promote a more effective monoclinic-tetragonal transformation, as it was shown in Figure 5. In addition, it is reasonable to expect that a second toughening mechanism could take place, due to some degree of crystallization of molten glass. This transformation would toughen the glass matrix in a similar way as leucite in vitroceramics.

On the fracture toughness by indentation strength (IS), the $\mathrm{K}_{\mathrm{IC}}$ from groups 2 and 3 (Figure 4), did not fit on a single line as expected for a normal Weibull distribution. In spite of the small number of samples of each group $(n=12)$, those data were plotted considering two mutually excluding defect populations. It is reasonable to assume that the two indentation loads ( 59 and $98 \mathrm{~N}$ ) affected the mechanical behavior of ZTA samples, exhibiting a rising $\mathrm{R}$-curve. Other authors ${ }^{2,22,23}$ also observed that a higher indentation load overestimated $\mathrm{K}_{\mathrm{IC}}$ from (IS) tests. This behavior could be due to the following facts:

Lateral cracks could be more effective on deviating radial cracks with an increase in indentation load ${ }^{22}$. As in groups 2 and 3 the defect population introduced by surface treatments is relatively small, on the higher load samples the critical factor for catastrophic crack propagation would be ruled by the defects introduced by indentation.

The radial tensile stresses are $70 \%$ of the peak value directly below the applied load, decreasing to $20 \%$ or less at a small radial distance from the loading piston ${ }^{23,24}$. These observations support the conclusion that radial cracks introduced by a higher indentation load tend to grow into a reduced tensile stress field, leading to a certain independence of indentation load on $\mathrm{K}_{\mathrm{IC}}$.

Scanning electron microscopy (SEM) of the fractured surface of the ZTA (Figure 7), shows a crack propagating through the glass matrix, contouring an alumina particle and being held by a group of zirconia particles. Some studies ${ }^{21}$ reported that depending on the morphology of alumina particles another toughening mechanism due

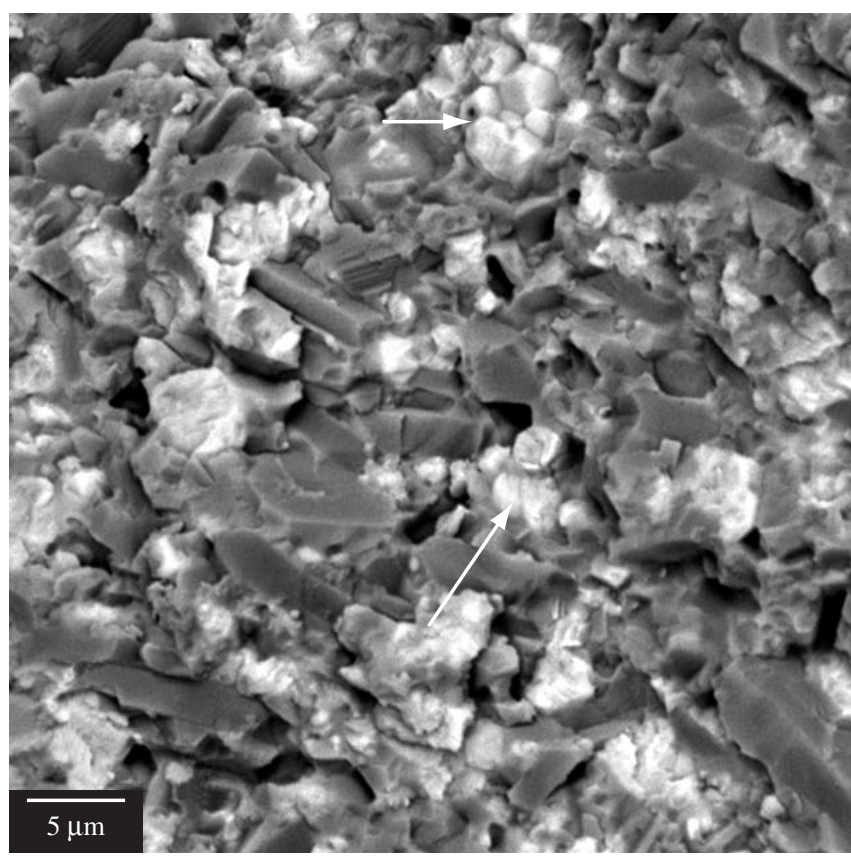

(a)

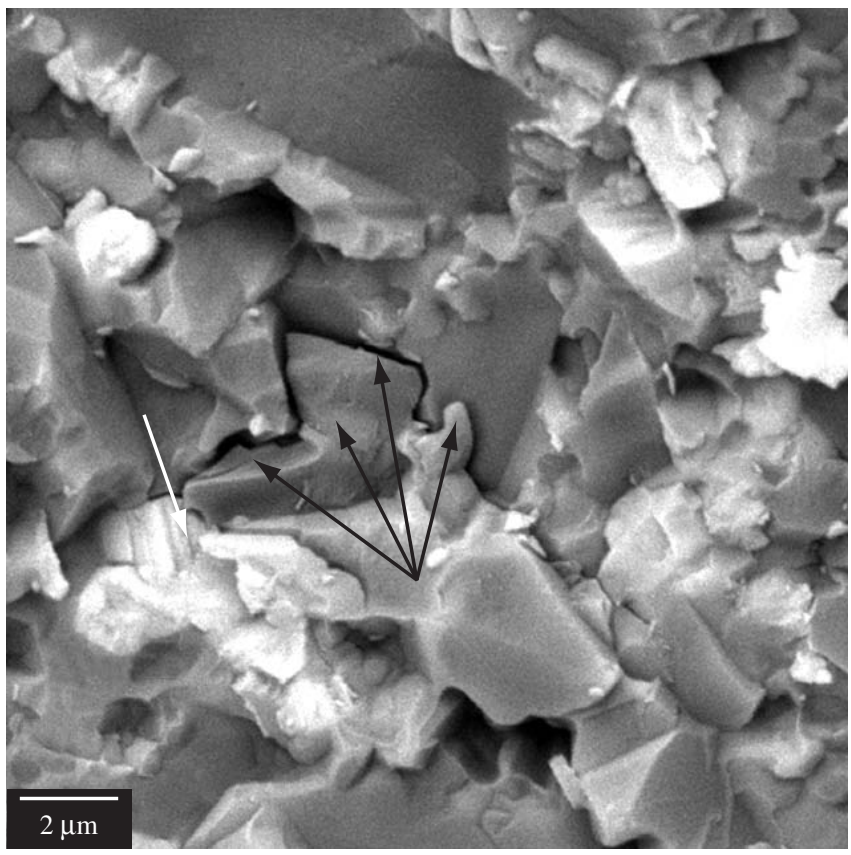

(b)

Figure 7. Scanning electron micrograph of an infiltrated ZTA fractured sample. Note small zirconia agglomerates (white arrows) dispersed among alumina grains and a crack contouring an alumina grain (black arrows), being held by one of these agglomerates. 
to the anisotropic growth of alumina particles during glass infiltration would be expected.

\section{Conclusions}

- Infiltrated ZTA disks surface treated by grinding (group 1), presented the lowest $\mathrm{K}_{\mathrm{IC}}$, due to the large and deep cracks introduced by grinding;

- Infiltrated ZTA disks surface treated by sandblasting (group 2) presented a $\mathrm{K}_{\mathrm{IC}}$ higher than group 1, due to the shallow and well distributed small cracks which led to a greater reliability;

- Infiltrated ZTA disks surface treated by grinding followed by sandblasting and annealing (group 3) presented the highest $\mathrm{K}_{\mathrm{IC}}$. In this case, the heat treatment recovered some tetragonal zirconia lost during surface treatments;

- Apparent Weibull distribution of fracture toughness tests of all groups, mainly groups 2 and 3, revealed that the indentation load influenced $\mathrm{K}_{\mathrm{IC}}$. This could be due to the small number of samples of each group, kind of flexure test employed (biaxial flexure test) and introduction of lateral cracks which increases with indentation load. As a consequence, two mutually excluding populations were observed; and

- Grinding and sandblasting may promote a toughening mechanism to ZTA, unless its surface compressive layer is sufficient shallow. Otherwise they will promote stress concentration sites decreasing its toughness. An annealing after grinding and sandblasting may recover some tetragonal phase lost during those surface treatments.

\section{References}

1. Vita Zahnfabrik, Vita In-Ceram ${ }^{\circledR}$ Alumina instruction manual. Bad Säkingen, Germany: Vita Zahnfabrik Edt; 2000.

2. Guazzato M, Albakry M, Swain M, Ironside. J. Mechanical properties of In-Ceram ${ }^{\circledR}$ Alumina and In-Ceram ${ }^{\circledR}$ Zirconia. Int. J. Prosthodontics. 2002; 15(4):339-346.

3. Stevens R. Engineering properties of zirconia and zirconia ceramics. From An Introduction to Zircônia, Magnesium Elektron Publication $n^{\circ} 113$. UK, Manchester, Magnesium Elektron Ltd. Publication; 1986. p. 1-56.

4. Kosmak T, Oblak C, Jevnikar P, Funduk N, Marion L. The effect of surface grinding and sandblasting on flexural strength and reliability of Y-TZP ceramic. Dental Materials. 1999; 15(6):426-433.

5. Swain M, Hannink R. Metastability of the martensitic transformation in a 12 mol\% ceria-zirconia alloy: Grinding studies. Journal of the American Ceramic Society. 1989; 72(1):1358-1364.

6. Garcia M, Page S, Llopis J. Relationship between mechanical grinding and photoluminescence of zirconia toughened alumina ceramics. Materials Science Engineering A. 2002; 325(1-2):302-306.

7. Luthardt R, Holzhüter M, Rudolph H, Herold V, Walter M. CAD/ CAM machining effects on Y-TZP zirconia. Dental Materials, 2004; 20(7):655-662.
8. Matsuzawa M, Horibe S. Resistance against crack nucleation and propagation in yttria doped tetragonal zirconia ceramics. Materials Science Engineering A. 2002; 333(1-2):199-207.

9. Lawn BR. Physics of Fracture. Journal of the American Ceramic Society. 1983; 66(2):83-91.

10. Proos K, Swain M, Steven G. Finite element analysis studies of an all ceramic crown on a first premolar. International Journal Prosthodontics; 2002; 15(4):404-412.

11. Green DJ. A technique for introducing surface compression into zirconia ceramics. Journal American Ceramic Society. 1983; 66:C-178-179.

12. Luthardt RG, Holzhüter M, Sandkuhl O, Herold V, Schnapp J, Kuhlisch E. Reliability and properties of ground Y-TZP zirconia ceramics. Journal of Dental Research. 2002; 81(7):487-491.

13. Guazzato M, Albakry M, Quach L, Swain MV. Influence of surface and heat treatments on the flexural strength of a glass-infiltrated alumina/zirconia-reinforced dental ceramic. Dental Materials. 2005; 21(5):454-463.

14. Moon W, Ito T, Uchimura S, Saka H. Toughening of ceramics by dislocation sub-boundaries. Materials Science and Engineering A. 2005; 387-389: 837-839.

15. Chantikul P, Anstis GR, Lawn BR, Marshall DB. A critical evaluation of indentation techniques for measuring fracture toughness: II - Strength method. Journal of American Ceramic Society. 1981; 64(9):539-543.

16. Kruskal WH, Wallis WA. Use of ranks in one-criterion variance analysis. Journal of American Statistical Association. 1952; 47(260):583-621.

17. Kruskal WH, Wallis WA. Errata to Use of ranks in one-criterion variance analysis. Journal of American Statistical Association. 1952; 47(267):907-911.

18. Weibull WA statistical distribution function of wide application. Journal of Applied Mechanics. 1951; 18(3):293-297.

19. Garvie R, Nicholson P. Phase analysis in zirconia systems. Journal of American Ceramic Society. 1972; 55(67):303-305.

20. Gregory G, Burger W, Sergo V. Piezo-spectroscopy analysis of residual stresses in zirconia toughened alumina ceramics: The influence of the tetragonal to monoclinic transformation. Materials Science and Engineering $A ; 1999.271(1): 401-406$.

21. Guazzato M, Albakry M, Ringer S, Swain MV. Strength, fracture toughness of all-ceramic materials. Part II - Zirconia based dental ceramics. Dental Materials; 2004; 20(5):449-456.

22. Sherrer S, Denry I, Wiskott HW. A comparison of three fracture toughness testing techniques using a dental glass and a dental ceramic. Dental Materials. 1998; 14(4):246-255.

23. Higgs WAJ, Lucksanasombool P, Higgs RJED, Swain M. Evaluating acrylic and glass-ionomer cement strength using the biaxial flexure test. Biomaterials. 2001; 22(12):1583-1590.

24. Jeong SM, Park SE, Lee HL. Fracture behavior of alumina ceramics by biaxial ball-on-three-ball test. Journal of European Ceramic Society. 2002; 22(7):1129-1135 